\title{
GAMBARAN PERILAKU SAAT MENSTRUASI PADA MAHASISWA SEMESTER III PRODI JENJANG D IV FAKULTAS ILMU KESEHATAN UNIVERSITAS 'AISYIYAH YOGYAKARTA
}

\author{
DESCRIPTION OF BEHAVIOR WHETHER MENSTRUAL AT SEMESTER STUDENTS III \\ PRODI JENJANG D IV FACULTY OF HEALTH SCIENCE \\ UNIVERSITY'AISYIYAH YOGYAKARTA
}

\author{
Belian Anugrah Estri \\ Program Studi DIV Bidan Pendidik Universitas ‘Aisyiyah Yogyakarta \\ Email : belianestry@gmail.com
}

\begin{abstract}
ABSTRAK
Minimnya informasi dan kurangnya peran orangtua dalam pendidikan menstruasi sering menjadi persoalan yang membuat remaja salah dalam memberikan keputusan. Remaja yang kurang informasi tentang kesehatan reproduksi dikhawatirkan tidak bisa mempersiapkan mental mereka untuk menghadapi haid. Tidak dapat dipungkiri lagi kebutuhan remaja akan informasi, pendidikan dan pelayanan kesehatan reproduksi masih belum dapat di penuhi dengan baik, padahal masalah kesehatan reproduksi terjadi justru akibat remaja kekurangan informasi yang benar dan bertanggung jawab sehingga mereka mengakses informasi yang keliru. Berdasarkan hasil Pengamatan di Universitas 'Aisyiyah pada mahasiswa semester III Prodi jenjang DIV Bidan Pendidik, masih banyak di temukan mahasiswa yang kurang paham terkait perilaku yang baik selama menstruasi salah satunya adalah waktu penggantian pembalut. Tujuan Penelitian ini adalah untuk mengetahui gambaran perilaku saat menstruasi. Metode penelitian ini adalah kuantitatif dengan pendekatan waktu cross sectional. Teknik sampling dalam penelitian ini adalah porposive sampling dan proportionate stratified random sampling didapatkan hasil sebanyak 87 responden. Teknik analisis dilakukan secara diskriptif narative. Penelitian ini menunjukkan ada perilaku saat menstruasi pada mahasiswa semester 3 DIV Bidan Pendidik di Unversitas 'Aisyiyah Yogyakarta sebagian besar berperilaku baik yaitu sebanyak 51 responden (58,6\%) dan tidak ada responden yang berperilaku kurang .
\end{abstract}

Kata Kunci $\quad$ : Menstruasi, Perilaku Saat menstruasi

\begin{abstract}
The lack of information in menstruation education is often a problem that makes teenagers wrong in making decisions. The purpose of this study was to determine the description of behavior during menstruation. Teenagers who are less informed about reproductive health feared could not prepare their mental to deal with menstruation. It is undeniable that teenagers' needs for information, education and reproductive health services still can not be fulfilled properly, whereas reproductive health problems occur precisely because adolescents lack the right and responsible information so that they access misinformation. Based on the observations at the University of 'Aisyiyah in the third semester students of DIV Program Bidan Pendidik, there are still many students who do not understand related to good behavior during menstruation, one of them is the time of replacement napkin. This research method is quantitative with cross sectional time approach. Sampling technique in this research is porposive sampling and proportionate stratified random sampling, obtained result as many as 87 respondents. The analysis technique is done in narrative descriptive. This research indicates that there are behavior during menstruation at 3rd semester student. DIV Bidan Pendidik at University of Aisyiyah Yogyakarta mostly have good behavior that is 51 respondent (58,6\%) and no respondent that behave less.
\end{abstract}

Key words $\quad$ : Menstruation, Behavior during menstruation

\section{PENDAHULUAN}

Untuk mewujudkan Millenium Development Goals (MDGs) tahun 2015 diperlukan perilaku proaktif untuk memelihara dan meningkatkan kesehatan, mencegah resiko terjadinya penyakit, melindungi diri dari ancaman penyakit serta berpartisipasi aktif dalam gerakan kesehatan masyarakat (Departement 
Kesehatan RI, 2007). Berdasarkan hasil sensus penduduk Indonesia bulan Agustus 2010, jumlah remaja di Yogyakarta kelompok remaja usia 10-14 tahun adalah sekitar 257.806 orang remaja dan kelompok remaja usia 15-19 tahun adalah sekitar 275.730 orang remaja, sehingga untuk menciptakan pribadi yang matang dari seorang remaja kesehatan reproduksi juga perlu diperhatikan (Badan Pusat Statistika, 2010).

Remaja yang kurang informasi
tentang
dikhawatirkan tidak bisa mempersiapkan mental mereka untuk menghadapi haid. Tidak dapat dipungkiri lagi kebutuhan remaja akan informasi, pendidikan dan pelayanan kesehatan reproduksi masih belum dapat di penuhi dengan baik, padahal masalah kesehatan reproduksi terjadi justru akibat remaja kekurangan informasi yang benar dan bertanggung jawab sehingga mereka mengakses informasi yang keliru (Dianawati, 2003).

Hasil penelitian Ardani, 2011 terhadap 133 siswa SMA di Yogyakarta, menunjukkan remaja putri sebanyak 93 orang $(69,9 \%)$ memiliki pengetahuan baik, 39 orang $(29,3 \%)$ memiliki pengetahuan cukup $(75,2 \%)$ dan 1 orang $(0,8 \%)$ memiliki pengetahuan kurang. Sedangkan berdasarkan perilaku remaja 57 orang $(42,9 \%)$ memiliki perilaku baik dan 76 orang $(57,1 \%)$ memiliki perilaku cukup dalam menjaga kebersihan alat genetalianya saat menstruasi. Pada saat menstruasi seharusnya perempuan benarbenar dapat menjaga kebersihan organ reproduksi secara "ekstra" terutama pada bagian vagina, karena kalau tidak dijaga kebersihannya, akan menimbulkan mikroorganisme yang berlebih sehingga mengganggu fungsi organ reproduksi (PKBI DIY, 2008).

Berdasarkan hasil Pengamatan di Universitas 'Aisyiyah pada mahasiswa semester III Prodi jenjang DIV Bidan Pendidik, masih banyak di temukan mahasiswa yang kurang paham terkait perilaku yang baik selama menstruasi salah satunya adalah waktu penggantian pembalut. Peneliti juga mendapatkan keterangan dari mahasiswa saat kegiatan belajar mengajar semester III ini, dikarenkan saat pembahasan kesehatan reproduksi masih didapatkan mahasiswa yang belum paham terkait perilaku yang baik saat menstruasi salah satunya terkait waktu penggantian pembalut serta pengkonumsian tablet fe selama menstruasi. Mengingat mahasiswa tersebut merupakan mahasiwa kesehatan yang merupakan calon bidan, sehingga permasalahan tentang kesehatan reproduksi pada diri sendiri seharusnya harus paham terlebih dahulu sebelum mahsiswa tersebut terjun kelahan dan memberikan asuhan kepada orang lain. Berkaitan dengan hal tersebut, peneliti mencoba meneliti tentang gambaran perilaku saat menstruasi pada mahasiswa semester III Prodi Jenjang D IV Fakultas Ilmu Kesehatan Universitas 'Aisyiyah Yogyakarta 2016.

\section{METODE PENELITIAN}

Penelitian ini menggunakan metode kuantitatif dengan pendekatan waktu (metode cross sectional). Pada penelitian ini akan dilakukan survey dengan menggunakan kuesioner untuk mendapatkan Perilaku Saat Menstruasi Pada Mahasiswa Semester III Prodi Jenjang D IV Fakultas Ilmu Kesehatan Universitas 'Aisyiyah Yogyakarta 2016

Data-data penelitian ini akan di analisis secara diskriptif narative. Penelitian ini bertujuan untuk Perilaku Saat Menstruasi Pada Mahasiswa Semester III Prodi Jenjang D IV Fakultas Ilmu Kesehatan Universitas 'Aisyiyah Yogyakarta 2016.

Populasi adalah keseluruhan objek penelitian (Notoatmojo, 2005). Populasi dalam penelitian ini adalah semua Mahasiswa Semester III Prodi Jenjang D IV Fakultas Ilmu Kesehatan Universitas 'Aisyiyah Yogyakarta 2016 yang berjumlah 134 mahasiswa. 
Pengambilan sampel pada penelitian ini menggunakan teknik purposive sampling dan Proportionate Stratified Random Sampling. Sampel pada penelitian ini Mahasiswa Semester III Prodi Jenjang D IV Fakultas Ilmu Kesehatan Universitas 'Aisyiyah Yogyakarta 2016 kelas A dan B setelah dilakukan penelitian didapatkan responden yang memenuhi kriteria inklusi sejumlah 87 responden.

Alat yang digunakan dalam mengumpulkan data adalah dengan kuesioner tertutup yakni kuesioner yang sudah disediakan alternatif pilihan jawabanya sehingga responden tinggal memilih. Sebelum diberikan kepada responden, kuesioner diuji validitas dan reabilitasnya dengan sejumlah 25 pernyataan.

Metode pengumpulan data dilakukan oleh peneliti dan tim. Pembagian kuesioner dilakukan dalam waktu yang bersamaan yang akan di sebarkan oleh tim. Selanjutnya peneliti membagikan pengantar kuesioner (informed concent) dan kuesioner kepada responden. Setelah dibagikan kepada responden, kemudian peneliti menjelaskan cara mengisi kuesionernya. Kuesioner yang telah diisi dikembalikan responden ke peneliti kemudian diteliti kelengkapannya.

\section{HASIL DAN PEMBAHASAN}

Penelitian ini dilakukan di Universitas 'Aisyiyah Yogyakarta yang terletak di Jl.Ring Road Barat 63 Mlangi, Nogotirto, Gamping, Sleman, Yogyakarta. Dilakukan pada mahasiswa semester III Program Studi DIV Bidan Pendidik. Sampel pnelitian ini diambil dengan karakteristu umur dan perilaku saat menstruasi.

dalam lingkungan UNISA sudah terdapat organisasi yang bergerak dalam bidan kesehatan salah satunya kespro yaitu PIK M. Dimana organisasai tersebut sebagai pusat informasi mahasiwa tentang kespro.

\section{Gambaran Karakteristik Responden}

Responden dalam penelitian ini adalah mahasiswa semester III Program Studi DIV Bidan Pendidik Reguler di Universitas
'Aisyiyah Yogyakarta sebanyak 87 responden. Karakteristik pada mahasiswa sebagai responden penelitian dikelompokkan berdasarkan usia mahasiswa.

Tabel 1. Distribusi Frekuensi Karakteristik Responden Berdasarkan Usia di Universitas 'Aisyiyah Yogyakarta Tahun 2016

\begin{tabular}{lcc}
\hline Usia & Frekuensi & $\begin{array}{c}\text { Persentase } \\
(\%)\end{array}$ \\
\hline 18 Tahun & 38 & $43,7 \%$ \\
19 Tahun & 27 & $31,1 \%$ \\
20 Tahun & 21 & $24,1 \%$ \\
21 Tahun & 1 & $1,1 \%$ \\
Total & 87 & $100 \%$ \\
\hline
\end{tabular}

Sumber: data primer 2016

Berdasarkan Tabel 1. didapatkan data dari 87 reponden yang diteliti, paling banyak pada usia responden 18 tahun yaitu sebanyak 38 responden $(43,7 \%)$, dan usia paling sedikit yaitu 21 tahun yaitu 1 responden $(1,1 \%)$.

\section{Distribusi Perilaku Saat Menstruasi}

Tabel 2. Distribusi Frekuensi Perilaku Saat Menstruasi pada mahasiswa Program Studi DIV Bidan Pendidik Reguler di Universitas 'Aisyiyah Yogyakarta

\begin{tabular}{clcc}
\hline No. & Kategori & Frekuensi & $\%$ \\
\hline 1. & Baik & 51 & 58,6 \\
2. & Sedang & 36 & 41,4 \\
3. & Kurang & 0 & 0 \\
& Jumlah & 87 & 100 \\
\hline
\end{tabular}

Sumber Data: Data Primer 2016

Berdasarkan tabel 2. dapat diketahui bahwa perilaku mahasiswa semester III Program Studi DIV Bidan Pendidik Reguler di Universitas 'Aisyiyah Yogyakarta sebagian besar adalah baik yaitu sebanyak 51 responden $(58,6 \%)$, dan dengan kategori sedang sejumlah 36 responden $(41,4 \%)$.

\section{Distribusi Rekapitulasi Hasil Dari Usia Dan Perilaku Responden Saat Menstruasi}

Tabel 3 Distribusi Frekuensi

Karakteristik Responden Berdasarkan Usia dan kategori perilaku saat menstruasi di 
Universitas 'Aisyiyah Yogyakarta Tahun

\begin{tabular}{llcc}
\multicolumn{4}{c}{2016} \\
\hline Usia & Kategori & Frekuensi & $\%$ \\
\hline 18 tahun & Sedang & 14 & 16,1 \\
& Baik & 24 & 27,6 \\
19 tahun & Sedang & 11 & 12,6 \\
& Baik & 16 & 18,4 \\
20 tahun & Sedang & 11 & 12,6 \\
& Baik & 10 & 11,5 \\
21 tahun & Sedang & 1 & 1,2 \\
Total & & 87 & 100 \\
\hline
\end{tabular}

Berdasarkan tabel 3. Dapat diketahui bahwa kategori perilaku saat menstruasi paling banyak dalam kategori perilaku baik di usia 18 tahun yaitu sebanyak 24 responden $(27,6 \%)$ dan yang paling sedikit di usia 21 tahun dengan kategori sedang yaitu 1 responden $(1,2 \%)$.

Hasil penelitian menunjukan dari 87 responden diketahui bahwa perilaku mahasiswa saat menstruasi sebagian besar adalah baik yaitu sebanyak 51 responden $(58,6 \%)$ dan yang terkecil adalah sedang sebanyak 36 responden (41,4\%). Perilaku dalam penelitian ini merupakan tindakan responden yang dapat diamati secara langsung maupun tidak langsung saat menghadapi menstruasi.

Hasil Penelitian ini menunjukkan bahwa perilaku responden saat menstruasi adalah baik. Perilaku baik dalam menstruasi adalah hal yang memang harus diperhatikan dan diajarkan pada remaja saat ini. Hal itu dikarenakan masa remaja yang merupakan masa peralihan dari masa anak-anak ke masa dewasa meliputi semua perkembangannya yang dialami sebagai persiapan memasuki masa dewasa sehingga pertumbuhan seks merupakan faktor yang penting. Oleh karena itu perilaku remaja dalam menghadapi menstruasi pantas menjadi perhatian agar mereka dapat menerapkan perilaku yang positif dan sehat (Widjanarko, 2006).

Melihat dari hasil terkait perilaku saat menstruasi yang paling banyak adalah baik pada responden yaitu mahasiswa semester III Prodi DIV Bidan Pendidik Universitas
'Aisyiyah Yogyakarta merupakan sebuah bentuk apresiasi yang sangat bagi dari calon tenaga kesehatan yaitu bidan. Tidak dapat dipungkiri sikap baik tersebut dapat dikarenakan informasi atau tambahan pengetahuan selama respondan tersebut mengikuti perkuliahan di Universitas 'Aisyiyah Yogyakarta. Perkuliahan yang mendukung responden (mahasiswa) dalam memperoleh informasi yang benar dalam menstruasi salah satunya dalam mata kuliah kesehatan reproduksi, dimana dalam perkulihan tersebut di jabarkan materi terkait mmenstruasi sevara menyeluruh.

Kegiatan yang di canangkan oleh pemerintah yang saat ini sudah berjalan secara berkelanjutan yaitu Duta Genre yang dinaungi oleh BKKBN (Badan Kependudukan Dan Keluarga Berencana Nasional). Duta genre dalam perjalanan kiprahnya sangat membantu dalam pemberian motivasi langsung ke remaja khususnya mahasiswa karena programprogram yang di jalankan sanagat menginspirasi dan memberikan contoh yang baik untuk berperilaku ke arah yang baik, salah satunya dalam perilaku saat menstruasi. Duta Genre sebagai penyambung pesan dari BKKBN kepada generasi muda di seluruh Indonesia agar memiliki pemahaman yang baik tentang keluarga berencana, kependudukan, dan pembangunan keluarga (Kompasiana, 2015). Duta Genre tidak hanya berada di jajaran Universitas tetapi juga masuk di jenjang SMA, sehingga terobosan dalam program mencerdaskan remja dalam paham terkait kesehatan sangat mumpuni. Hal tersebut merupakan langkah strategis dimana dengan memberikan contoh sosok remaja yang memang pantas menjadi panutan dengan memiliki kepribadian yang baik, integritas yang mumpuni, dan kemampuan berbicara di depan publik yang baik.

Lingkungan di Universitas ' Aisyiyah Yogyakarta juga sudah di fasilitasi dengan organisasi mahasiswa yang di dukung keberadaanya oleh civitas akademik. 
Organisasi tersebut bergerak di bidang kesehatan reproduksi. Nama organisasi tersebut adalah PIKM (Pusat Informasi Konseling Mahasiswa Mahkota Puri), dimana peran aktif dari mahasiswa yang menggeerakan oraganisasi tersebut di bantu dengan peran dosen pendamping yang sangat mumpuni. sehingga tidak ada alasan mahasiswa tidak tau, khususnya mahasiswa putri. Dimana informasi yang sudah tersedia harus dimanfaatkan dengan baik guna menjadikan pribadi yang baik dan berguna, serta kelak saat menjadi seorang tenaga kesehatan bisa memberikan contoh yang baik bagi pasien maupun teman sebayadan sejawat.

Informasi baru mengenai suatu hal memberikan landasan kognitif bagi terbentuknya perilaku dan perilaku hal tersebut, maka semakin banyak informasi baru yang diperoleh responden tentang kesehatan reproduksi akan mendukung seseorang berperilaku positif saat menstruasi. Penelitian menunjukkan perilaku saat menstruasi paling banyak kategori baik karena pengaruh usia yang masih remaja (17 tahun), dikarenakan pola pikir dan pemahaman yang baik, serta a kemauan dan kemampuan responden memanfaatkan fasilitas internet yang sudah disediakan di universitas untuk mendapatkan/mengakses informasi tentang kesehatan reproduksi khususnya dalam perilaku saat menstruasi serta ada mata kuliah yang mendukung, sehingga dengan informasi yang cukup responden mendapatkan suatu pembelajaran tentang perilaku yang baik saat menstruasi.

Responden yang berpengetahuan baik sadar akan masa peralihan dari masa anakanak ke masa dewasa meliputi semua perkembangannya yang dialami sebagai persiapan memasuki masa dewasa sehingga pertumbuhan seks merupakan faktor yang penting dan akan berperilaku baik saat menstruasi. Hasil penelitian ini didukung oleh penelitian Wahyuhidaya (2008), bahwa adanya hubungan tentang tingkat pengetahuan kesehatan reproduksi dengan sikap remaja putri dalam menghadapi menarche. Pengetahuan remaja putri yang semakin baik tentang kesehatan reproduksi mendukung seseorang untuk lebih bersikap positif dalam menghadapi menarche.

Hal ini merupakan jawaban dari sikap yang memang sudah baik dalam berperilaku saat menstruasi, serta tidak ada responden yang memiliki sikap kurang dalam perilaku menstruasi. Lingkungan juga berpengaruh penting dalam membantu untuk menumbuhkan perilaku yang baik, hal ini dibantu dengan teman sebaya yang masih bisa dikatakn seumuran, serta proses ingin tahu yang di fasilitasi dari universitaas, meliputi perpustakaan, internet serta peran dosen yang selalu ada jika mahasiswa ada masalah , dan yang terpenting adalah lingkungan belajar responden ini merupakan lingkungan di dunia kesehatan dan didalamnya hanya ada perempuan. dimana dengan hal tersebut roses bertukar pikiran sangat mendukung dalam peran responden melakukan perilaku yang baik saat menstruasi. Outcome dari penelitian ini sangat berguna untuk menilai perilaku sehat bagi para calon bidan, yang nantinya mereka juga akan kembali memberikan asuhan pada perempuan di sepanjang siklus hidupnya. Variabel yang berpengaruh terhadap perilaku saat menstruasi remaja, diantaranya pengetahuan, pengalaman pribadi, pengaruh orang lain yang dianggap penting, kebudayaan, media massa, emosional, lembaga pendidikan dan agama.

\section{SIMPULAN}

Berdasarkan hasil penelitian sebagian besar adalah saat menstruasi berperilaku baik yaitu sebanyak 51 responden $(58,6 \%)$, dan dengan kategori sedang sejumlah 36 responden $(41,4 \%)$, tidak ada yang memiliki perilaku yang kurang. Melihat dari hasil tersebut bisa dikatakn perilaku mahasiwa sudah baik didukung dengan lingkungan belajar, dengan mata kuliah yang mendukung, informasi yang tersedia dengan tersedianya internet (wifi) dan organisasi 
salah satunya PIKM, sebagai pusat informasi kesehatan yang mumpuni.

\section{DAFTAR PUSTAKA}

Biro Pustaka Statistik. 2010. Statistika Kesehatan Reproduksi Remaja. Depkes RI.

Dianawati, A. 2003a. Pendidikan Seks Untuk Remaja. Kawan Pustaka. Jakarta.

- 2003b. Pendidikan Seks Untuk Remaja. Kawan Pustaka. Jakarta.

Ahira, A. 2010. Peran Orang Tua Dalam mendidik Anak (http ://anneahira.com, diakses 17 Februari 2012.

PKBI DIY. 2008. Kesehatan pada alat reproduksi.

http://en.wikipedia.org/wiki/kesehatan

alat reproduksi, diakses tanggal 10 Februari 2012.
Notoatmodjo, S. 2005. Metodologi Penelitian Kesehatan. Jakarta. Rineka Cipta.

Wiknjosastro, Hanifa. 2005. Ilmu Kebidanan. Edisi ke-3. Jakarta: Yayasan Bina Pustaka.

Widjanarko. 2006. Remaja dan Pubertas. Rineka Cipta. Yogyakarta.

BKKBN .2015. Duta Genre untuk mahasiswa. diunduh tanggal 15 Juli 2017 di www.kompasiana.com 